\title{
PROMOTORES DE JUSTIÇA E NOVAS FORMAS DE ATUAÇÃO EM DEFESA DE INTERESSES SOCIAIS E COLETIVOS*
}

\section{Cátia Aida Silva}

"Todo mundo pensa que promotor só fica mexendo com papel." "O promotor tem que ir atrás, buscar os fatos." ${ }^{1}$

\section{Introdução}

A atuação dos promotores de justiça na defesa de novos direitos e interesses coletivos e sociais é o foco deste artigo. Minha finalidade é discutiras formas de atuação de um grupo de promotores de justiça no interior e na capital do Estado de São Paulo, por meio de dois tipos ideais construídos a partir do cotidiano destes profissionais. Pretendo argumentarque o estilo de atuação inaugurado por estes promotores, que fazem largo uso, inclusive, de procedimentos extrajudiciais, possui contomos fluidos, uma vez que, entre as atribuições constitucionais e a letra da lei - pontos principais do debate atual sobre o Ministério Público - , o promotor de justiça tem um significativo espaço para

* Este artigo está baseado no segundo capítulo de minha tese de doutorado, Novasfacetas da atuação dospromotores de justiça: um estudo sobre o Ministério Público e a defesa dos interesses sociais, apresentada ao Programa de Pós-Graduação em Ciência Política da Universidade de São Paulo em junho de 1999, tendo a orientação da professora Dra. Ruth Corrêa Leite Cardoso. definir suas prioridades e criar métodos de trabalho. Neste espaço vão operarvários elementos, como suas convicções, experiências advindas das diferentes áreas de especialização e escolhas feitas durante a carreira.

Na primeira seção do artigo é apresentado o contexto de transformações institucionais e legislativas que resultaram nas novas atribuições dos promotores de justiça na defesa de interesses sociais e coletivos. Na segunda seção, são discutidas algumas particularidades e características do universo dos promotores de justiça e, na terceira, as conexões entre velhas e novas práticas destes profissionais, além de algumas diferenças que marcam o exercício da profissão no interior e na capital. Por fim, a quarta seção dedica-se à apresentação dos tipos ideais e respectivas formas de atuação, a partir do grupo estudado, tentando mostrar os contornos fluidos que cercam as novas atribuições dos promotores de justiça.

Recentemente, surveys e pesquisas sobre o Ministério Público abriram um importante campo de investigações na área de ciências sociais (Sadek, 1997; Arantes, 1999). A perspectiva adotada neste artigo é bem distinta: empregando uma abordagem qualitativa e antropológica, o meu objetivo foi 
investigar "de perto" o universo dos promotores de justiça e suas práticas, fundamentais para que se possa compreender as importantes questões suscitadas pelo Ministério Público hoje no Brasil.

É preciso alertar que os tipos ideais apresentados e as conclusões aqui expostas referem-se à atuação dos promotores de justiça na defesa de direitos e interesses coletivos e sociais, como será detalhado adiante. A atuação dos promotores na área criminal suscitaria, provavelmente, considerações de outra ordem e inspiraria tipos ideais bem distintos. Ademais, estou me referindo a promotores que integram o Ministério Público de São Paulo, um dos mais importantes e articulados Ministérios Públicos estaduais do país.

Assim, as particularidades que cercam os promotores selecionados neste estudo estão devidamente apontadas ao longo do artigo e devem ser consideradas pelo leitor. Se a tentação de fazer generalizações sobre o Ministério Público esbarra nos limites das técnicas qualitativas empregadas, estas nos permitem explorar, no entanto, um vasto campo e "captar fatos e discursos qualitativamente significativos" (Pierucci, 1984, p. 29). A descrição antropológica não é a realidade estudada, como bem afirmou Geertz (1989), e o que se propõe, portanto, é uma interpretação sobre o que constitui a atuação dos promotores de justiça hoje. Uma interpretação que, procurando descer aos detalhes, às diferenças, e captar o "qualitativamente significativo", contribua para a compreensão das mudanças que atravessam o Ministério Público.

\section{Ministério Público e interesses metaindividuais}

Ao longo dos anos 1980 e 1990, o Ministério Público (MP), tradicionalmente conhecido como órgão de proteção a os fracos, reivindicou para si o papel de guardião da sociedade. A instituição foi sendo paulatinamente modificada por legislações sucessivas e, com a promulgação da Constituição de 1988, consolidou um novo perfil em todo o país, assumindo relevantes funções e garantindo aos seus membros as mesmas prerrogativas dos juízes (Macedo Jr., 1995; Mazzilli, 1996). Hoje, uma das atribuições constitucionais dos promotores de justiça é defender os chamados interesses metaindividuais, ou seja, interesses que afetam indivíduos, grupos da sociedade e enormes contingentes populacionais relacionados ao patrimônio público, meio ambiente, consumidor, idosos, crianças e outros interesses e direitos regulamentados por lei. ${ }^{2}$ Épreciso dizerque os membros dainstituição, especialmente do Ministério Público do Estado de São Paulo, contribuíram de forma decisiva para a introdução de leis de proteção aos interesses metaindividuais no Brasil. ${ }^{3}$

Tendo em vista a abrangência das questões implicadas pelos interesses metaindividuais - ou seja, in teresses in dividuais homogêneos, coletivos e difusos $^{4}$ - e o campo fecundo de possibilidades aberto por novos instrumentos judiciais e extrajudiciais criados por um conjunto de legislações recentes, o Ministério Público vem redefinindo o seu papel perante o sistema de justiça e a sociedade. Patrocinando causas públicas, atuando contra a comupção e intervindo em conflitos de grande alcance, o MP age como um ator político singular: situado na esferajurídica, tem a função de proteger interesses de grupos e segmentos da sociedade.

Vale insistirque tais mudançasnão podem ser dissociadas das importantes transformações que atingiram a sociedade e o direito no Brasil nas últimas décadas. As demandas e conflitos protagonizados por movimentos sociais, junto com as pressões pelo estabelecimento de um regime democrático, tornaram-se referência na reavaliação do funcionamento e da estrutura da justiça brasileira nos anos 70 e 80. As reivindicações e diagnósticos de vánios atores alimentaram propostas para a reforma de instituições e procedimentos jurídicos. O direito de inspiração liberal passou a ser cada vez mais identificado como instrumento útil ao regime autoritário, por enfraquecer demandas coletivas, e como fator de isolamento do Poder Judiciánio, incapaz de absorver as novas demandas. Além disso, guardadas as particularidades do processo brasileiro de redemocratização, problemas enfrentados porsistemas de justiça de vários países naquele contexto repercutiram aqui. Os conflitos sociais adquiriram cada vez mais o caráter de conflitos jurídicos, em face do surgimento de movimentos sociais, da expansão dos direitos e do welfare state. 
A tendência de especificação dos sujeitos, como definiu Bobbio, levou ao reconhecimento e regulamentação de novos direitos para mulheres, crianças, jovens, negros e idosos. ${ }^{5}$ Na Europa e nos Estados Unidos, a explosão de litigiosidade dos anos 70, creditada às demandas pelo reconhecimento de novos direitos e ao aumento contínuo de reivindicações postas ao poder público, teria introduzido, assim, conflitos que desafiavam a visão individualista de processo e tornavam inadequado o esquema de litígio como um mero two-party affair. Litígios que não mais diziam respeito a disputas entre indivíduos envolvendo direitos privados, mas que estavam ligados a disputas sobre a operação de políticas públicas que interessavam a um grande número de pessoas. Por outro lado, os sistemas de justiça se deparavam com situações geradas pelas condições inerentes às sociedades contemporâneas - nas quais as ações de poucos indivíduos podiam atingir populações inteiras, como na área do meio ambiente (Cappelletti et al., 1981; Kotz, 1981; Sousa Santos, 1995).

A introdução dosinteresses difusos e a regulamentação dos interesses metaindividuais no Direito brasileiro exigiram, como nos demais países, inovações no campo legislativo e jurídico. Estas inovações trouxeram uma nova abordagem do processo jurídico, que passou a ser visto como meio de participação do cidadão na vida pública e meio de implementação do interesse público. Os interesses difusos escapavam aos conceitos tradicionais subjacentes ao direito liberal, pois sua resolução colocava problemas de ordem política, uma vez que constituíam interesses de natureza coletiva e pública, a gerar conflitos entre grupos e a exigir a interferência govemamental (Mancuso, 1996). Não por acaso, muitas controvérsias surgiram no meio jurídico brasileiro ao longo do processo de regulamentação dos interesses metaindividuais, sobretudo porque, distintamente do que ocorre em vários outros países e do que desejavam alguns atores do campo juńdico, o Ministério Público reivindicou para si, ao lado de associações civis, a tutela dos interesses metaindividuais, ampliando suas atribuições na área cível. ${ }^{6}$

Embora os aspectos acima não possam ser aprofundados aqui, eles são importantes para a compreensão das formas de atuação desenvolvidas pelos promotores de justiça: como o MP tem agido na defesa dos interesses metaindividuais e quais as implicações de tão importante atribuição? Enfrentando a primeira questão, mas longe de esgotá-la, o artigo pretende contribuir para o debate da última.

\section{Ser promotor de justiça}

Como já foi dito, os promotores considerados neste estudo integram o Ministério Público de São Paulo, o maior, mais rico e um dos mais influentes Ministérios Públicos estaduais do país. ${ }^{7}$ Do grupo estudado, a maioria havia atuado prioritariamente em áreas relacionadas à questão dos interesses difusos e coletivos ao longo da carreira. Assim, é preciso terem mente que a trajetónia destes promotores e a importância dada pelos mesmos aos interesses metaindividuais demarcam as suas formas de atuação e alimentam as suas interpretações sobre o papel do Ministério Público.

O saber jurídico, a carreira e os debates intemos que têm lugar no Ministério Público concorrem para a formação do ethos que está por trás da linguagem e da ação dos promotores de justiça. As diferentes formas de atuação adotadas pelos promotores refletem, sem dúvida, distintas formações, opiniões políticas e cargos ocupados no decorrer da carreira. Nas falas, porém, eles se revelam como uma categoria profissional do campo jurídico, cuja linguagem e cuja postura estão pontuadas por uniformidades. Da formação jurídica e da organização da carreira brotam os jargões, exemplos e argumentos usados com regularidade quando se trata de apresentara carreira para os leigos. Como já definiu Bourdieu, a delimitação do espaço da justiça implica, de fato, uma fronteira entre os especialistas, aqueles que podem utilizar e decodificar o saber juńdico, e os não-especialistas, desqualificados e impotentes para participare influenciar os procedimentos adotados neste espaço:

O campo judicial é o espaço social organizado no qual e pelo qual se opera a transmutação de um conflito directo entre partes directamente interessadas no debate juridicamente regulado entre 
profissionais que actuam por procuração e que têm de comum o conhecere o reconhecerda regra do jogo jurídico, quer dizer, as leis escritas e não escritas do campo [... ] (Bourdieu, 1989, p. 229)

A linguagem técnica jurídica cria a "atmosfera de oficialidade" e funciona como "distanciador", ao mesmo tempo em que imprime uniformidade à argumentação de todos os operadores do direito (Sousa Santos, 1988). Este saber técnico ou "discurso argumentativo" constitui a fonte da competência jurídica dos promotores e demais operadores do direito e, por conseguinte, sua fonte de poder.

A carreira demarca, por sua vez, um lugar comum a partir do qual os promotores se posicionam perante as demais carreiras jurídicas. A definição do papel e da posição do Ministério Público dentro do sistema de justiça esteve sempre presente na fala dos promotores ouvidos. Donde a comparação sistemática com os juízes: os promotores desejavam mostrar a relação de igualdade (vencimentos, garantias, respeitabilidade) que sua carreira guarda hoje com a dos juízes e, ao mesmo tempo, as diferentes atribuiçõ es que os separam da magistratura e que fazem deles agentes provocadores do Poder Judiciário. Nesta comparação com os juízes, os promotores de justiça demarcavam indiretamente suas diferenças em relação aos demais operadores jurídicos, sobretudo delegados e procuradores do Estado (advogados e representantes do Estado).

O concurso de ingresso no Ministério Público, os cursos, atividades e avaliações a que são submetidos os novos membros concorrem para integrá-los à instituição, ao iniciá-los no repertónio e na linguagem inerentes à carreira. A especialização proporcionada pela carreira estimula, nas maiores comarcas e na capital, o debate, o estudo e 0 intercâmbio de informações, atividades que podem ser apoiadas por certos órgãos administrativos. A realização periódica de congressos e seminários nacionais e estaduais reunindo a categoria, assim como de campanhas internas para os cargos eletivos dos órgãos superiores e da associação de classe, no Estado de São Paulo, criam espaços de formulação e discussão de temas jurídicos e problemas institucionais. Ressalte-se, assim, que as estratégias institucionais formuladas pelos membros do Ministério Público de São Paulo ao longo de décadas originaram um discurso que também penetra as falas e argumentos dos promotores. A formulação de estratégias institucionais por determinados grupos do MP paulista, difundidas e debatidas nos congressos e seminários da categoria, gera um discurso, entendido aqui como um conjunto de argumentos apresentados de forma não sistemática, pois que vulgarizados e disseminados entre os membros do Ministério Público. ${ }^{8}$

Antes de abordar a forma de atuação dos promotores, é necessário esclarecer alguns aspectos relativos ao funcionamento formal do Ministério Público, isto é, esclarecer como está estruturada a carreira e quais são as garantias constitucionais dos promotores para exercer suas novas atribuições, de acordo com a legislação.

Argumentam os especialistas, com base na Constituição e nas leis orgânicas nacional e estadual do Ministério Público, que inexiste subordinação hierárquica no Ministério Público (Mazzilli, 1997). Ou seja, devido à independência funcional, uma das principais garantias constitucionais estendidas aos membros do Ministério Público, estes teriam como limites, no cumprimento de suas funções, apenas as leis e a Constituição. Assim, promotores e procuradores de justiça não são considerados "funcionários públicos hierarquizados", não dependendo de portarias, instruções e ordens de órgãos superiores do Ministério Público para agir. A independência funcional lhes asseguraria, no cumprimento de suas atribuições constitucionais, liberdade perante os órgãos da própria instituição. ${ }^{9}$ Desta maneira, a independência funcional assegurada porlei pode, a princípio, fazercom que as formas de atuação variem enormemente de promotorpara promotor. As demais garantias constitucionais asseguradas aos promotores e procuradores de justiça são a vitaliciedade, inamovibilidade e irredutibilidade de vencimentos. Em virtude da vitaliciedade, a perda do cargo decorre somente de sentença judicial transitada em julgado; em função da inamovibilidade, os membros do Ministério Público não podem ser removidos de seu cargo ou função, exceto em caso de interesse público; a irredutibilidade de vencimentos impede redu- 
ções no nível salarial da categoria, a menos que a Constituição seja alterada (Gomes, 1989). Embora estas garantias constitucionais sejam amplas e dêem enorme flexibilidade aos membros do $\mathrm{MP}$, como se verá, existem, por outro lado, constrangimentos institucionais que afetam o trabalho dos promotores no dia-a-dia. Promotores e procuradores de justiça são considerados, por lei, os principais órgãos de execução da instituição, ou seja, os responsáveis pelas atividades-fim do Ministério Público. Mas o procurador-geral de justiça, chefe do Ministério Público, o Colégio de Procuradores, o Conselho Superior e a Corregedoria-Geral, órgãos superiores da instituição, exercem funções executivas e administrativas de extrema relevância - aspecto que não será possível explorar neste artigo, mas que é preciso sublinhar. ${ }^{10}$

Todos os promotores são recrutados por meio de concursos públicos, iniciando a carreira como substitutose permanecendo obrigatoriamente nesta função por dois anos. Nesta fase, não gozam de vitaliciedade e são enviados para onde houver necessidade de substituição de promotores de justiça. ${ }^{11}$ Passado este peńodo e sendo efetivamente integrados à carreira, os promotores assumem o trabalho em pequenas comarcas. ${ }^{12} \mathrm{Em}$ função da existência de vagas e também de acordo com seus interesses, eles vão sendo promovidos para comarcas maiores, que exigem um trabalho cada vez mais especializado. Primeiramente, o promotorassume comarcas de primeira entrância, no interior do estado, geralmente localizadas em cidades de pequeno porte, atuando na chamada "clínica geral", isto é, cuidando de processos relacionados a todas as áreas, pois geralmente é o único promotor. O passo seguinte na carreira consiste em assumir comarcas de segunda entrância, localizadas em cidades maiores. Nestas, 0 promotor geralmente trabalha ao lado de colegas e inicia-se em áreas jurídicas mais especializadas. As comarcas de terceira entrância, por sua vez, estão localizadas em cidades de grande porte do interior, litoral e região da Grande São Paulo. Nestas comarcas, dependendo do número de colegas que possui, o promotor pode assumir uma, duas ou, até mesmo, três áreas de especialização. A seguir, o promotor pode assumirum cargo na única comar- ca de entrância especial, localizada na capital do estado. Na comarca de entrância especial, o promotor tem a chance de se candidatar aos cargos mais especializados do Ministério Público paulista e de "perseguir promoções" até ter condições de galgar o último degrau da carreira, tornando-se procurador de justiça. Os membros do Ministério Público são promovidos na carreira mediante critérios de antiguidade e de merecimento. ${ }^{13}$

\section{Da assistência judiciária à defesa de interesses metaindividuais}

\footnotetext{
"O Ministério Público sempre esteve à frente dos problemas sociais."
}

O promotor de justiça costuma terum contato contínuo com a população das comarcas, sobretudo no interior. $\mathrm{O}$ atendimento ao público é uma das mais antigas atribuições do Ministério Público, por meio do qual os promotores orientam, informam, fazem encaminhamentos, recebem denúncias e reclamações. Esta atribuição tomou-se tradicional na instituição, mas não há registros precisos sobre 0 período em que começou a ser exercida pelos promotores de justiça (Mazzilli, 1987). Antes da Constituição de 1988, os promo tores de justiça eram responsáveis pela prestação de assistência judiciária aos necessitados nas localidades onde não existissem órgãos compententes para tal. Hoje, os promotores não têm mais o dever de prestar assistência judiciánia, mas o atendimento ao público persiste e constitui uma das mais significativas atribuições herdadas por eles, convivendo com as funções de promoção da ação penal, de fiscal da lei nos processos civis e de defesa dos interesses metaindividuais.

O atendimento ao público é uma importante fonte de informações sobre os problemas da localidade. Como o juiz, o promotoré visto como uma autoridade neutra porque não pertence à "elite da cidade", além de confiável porque "está passando ali com todas as garantias constitucionais". ${ }^{14}$ Mas, diferentemente do juiz, o promotor faz atendimento ao público, às vezes diária, às vezes semanalmente, orientando, resolvendo casos por meio de 
"um simples telefonema", investigando denúncias sem identificar o denunciante e encaminhando moradores para serviços públicos. Muitos casos vão parar nos órgãos estatais de assistência judiciária, outros dão origem a investigações e processos propostos pelo Ministério Público. Os promotores afirmam que até mesmo pessoas com plenas condições de "tocar uma ação civil pública" contra violações praticadas por autoridades, comerciantes ou outros moradores da localidade "batem na porta do gabinete do promotor" porque sentem "medo das conseqüências". Muitas vezes, o promotor "liga para o secretário de Saúde, que liga para o prefeito e resolve uma situação na qual a pessoa teria que percorrer um rosário".

Por isso, os "comarcanos" do interior aprenderam a buscar orientação no gabinete do promotor. Segundo alguns autores, viria desta prática a expressão promotor público, designando o caráter público do trabalho exercido pelo promotor de justiça e consagrando a imagem do Ministério Público como órgão de proteção aos fracos. O papel dos promotores na "composição amigável" de partes em conflitos é também conhecido nos meiosjuńdicos. Comentando a presença da função conciliativa na tradição juńdica brasileira, Grinover afirma: "[... ] a pouca fortuna e a deturpação das funções do juiz de paz brasileiro não significavam indiferença da nação às vias conciliativas. Muito pelo contrário. Estas sempre foram bastante utilizadas pelos meios informais representados pelos membros do Ministério Público, sobretudo no interior do País." (Grinover et al., 1988, p. 289). ${ }^{15}$

Ademais, os promotores que trabalham nas comarcas do interior são obrigados a residir nas mesmas, como os juízes. Caso permaneçam por um tempo razoável nestas circunscrições judiciárias, precisam levar a família, alugar casas ou hospedar-se em pousadas e hotéis, matricular os filhos nas escolas disponíveis, conhecer os recursos que a localidade oferece, participar talvez dos eventos locais, tornar-se objeto da curiosidade e do assédio das "pessoas importantes" da municipalidade, receber, quem sabe, uma homenagem da Câmara Municipal ou da Prefeitura e entrar em contato, enfim, com os moradores e seus problemas cotidianos. No interior, os fatos "chegam" mais rapida- mente aos gabinetes dos promotores, seja as reclamações dos pais sobre as novas exigências das escolas estaduais, os boatos sobre um provável "desvio de verbas da creche" e denúncias sobre irregularidades nas eleições municipais, seja os comentários dos moradores a respeito das deficiências do transporte coletivo ou do loteamento clandestino que ameaça os mananciais da região.

Utilizando a considerável influência que possuem quando ocupam cargos em comarcas do interior, os promotores acabam encaminhando pessoas para serviços públicos e intermediando conflitos entre autoridades locais e a população, ou mesmo entre os próprios habitantes. As denúncias e reclamações sobre casos individuais que "chegam" aos gabinetes dos promotores podem dar origem a inquéritos civis e ações judiciais visando à resolução de questões mais abrangentes, ligadas à defesa de interesses coletivos e difusos. Assim, utilizando um atendimento que vem da antiga e tradicional função do Ministério Público na área cível, vários promotores procuram demarcar o seu novo espaço de atuação na defesa de interesses metaindividuais lançando mão dos novos instrumentos judiciais e procedimentos extrajudiciais consagrados na legislação recente.

O s promotores que ocupam cargos na capital também realizam atendimento ao público. Entretanto, no município de São Paulo, as denúncias e os fatos "chegam" ao gabinete do promotor geralmente via imprensa, partidos políticos, vereadores, deputados e organizações não-governamentais. A imprensa é uma fonte importantíssima de informações sobre irregularidades envolvendo políticos e órgãos públicos. Além disso, muitas promotorias e órgãos administrativos do Ministério Público, voltados a uma única área de atuação, costumam acompanhar a legislação e os fatos que ocorrem nas circunscrições de sua alçada. Promotorias e centros de apoio, por exemplo, costumam estabelecer um contato contínuo com órgãos públicos, conselhos municipais, organizações não-govemamentais, comissões legislativas e instituições ligadas à sua área de especialização. ${ }^{16}$

"Fazer Ministério Público no interior" tem um significado diferente para os promotores. A maioria deles considera que "a escola do promotor é o 
interior". As comarcas de primeira, segunda e terceira entrâncias propiciam muita "experiência e jogo de cintura”. Em primeiro lugar, porque levam os promotores a trabalhar com diversas legislações e áreas de especialização. Ademais, as proporções da comarca e a grande visibilidade fazem com que eles tenham de lidar com prefeitos, vereadores e políticos da localidade.

Para os promotores que decidiram "fazer carreira no interior", o trabalho na capital toma-se mais especializado e, por isso, corre o risco de tornar-se mais burocrático. A transferência para a capital acabaria comprometendo o que eles identificam como uma "forma mais firme de atuação do Ministério Público". O interior proporcionaria um tipo de trabalho no qual o contato com o público e o impacto das medidas tomadas pelo promotor são maiores. É curioso notar que promotores com diferentes estilos de atuação apontam os mesmos elementos para justificar sua preferência pelas comarcas do interior.

\section{Promotores de fatos e promotores de gabinete}

"E se o membro do Ministério Público cumprir efetivamente todas as atribuições que a legislação lhe confere, eu tenho a impressão de que a gente vai melhorar em muito o Brasil."

"Mas eu também acho o seguinte: ficou tudo para o Ministério Público, de repente.

Você tem um problema? Disque Ministério Público! E não é bem isso."

Para discutiras formas de atuação dos promotores, é preciso dizer que a capacidade de iniciativa do Ministério Público nas áreas de defesa da cidadania, meio ambiente, consumidor, criança e outras relacionadas a interesses metaindividuais advém do uso de instrumentos judiciais e, sobretudo, de instrumentos extrajudiciais regulamentados pelas leis de proteção a os interesses metaindividuais.

A ação civil pública foi o instrumento judicial criado para a defesa dos interesses difusos, sendo posteriormente estendida à proteção de interesses coletivos e individuais homogêneos. A ação civil pública trouxe significativas mudanças para o Direito brasileiro, uma vez que, ao responderàs particularidades inerentes aos interesses difusos, abriu um "largo espectro social de atuação, permitindo o acesso à justiça de certos interesses metaindividuais que, de outra forma, permaneceriam num certo limbo" (Mancuso, 1996, p. 19). O alcance da ação civil foi estendido porque, entre outras inovações, a lei prevê o cumprimento da obrigação de fazer ou não fazer, além da condenação em dinheiro. Isto significa que o réu pode sercondenado "ao cumprimento da prestação da atividade devida ou à cessação da atividade nociva" (Artigo 11). ${ }^{17}$

Os instrumentos extrajudiciais consistem no inquérito civil e numa série de providências ou atos - apurações, audiências, notificações - distintos da proposição de ações judiciais. Os instrumentos extrajudiciais, chamados procedimentos administrativos, são usados quando os promotores querem iniciar e desenvolver investigações relacionadas à violação de interesses e direitos previstos nas leis de proteção aos interesses metaindividuais. Ou quando passam a averiguar irregularidades e denúncias sobre as quais possuem pouca ou nenhuma evidência. Os procedimentos administrativos ou extrajudiciais englobam todos os atos que o promotor pode realizarpara "instruir" o inquérito civil ou o protocolado, isto é, o procedimento preparatório de inquérito civil. As leis de proteção aos interesses metaindividuais permitem, entre outras providências, que os promotores notifiquem cidadãos e autoridades públicas a prestar esclarecimentos e depoimentos, peçam o auxílio da polícia, requisitem informações, serviços e documentos de autoridades e de órgãos públicos e privados, façam inspeções e diligências investigatórias.

Mas a grande novidade reside no inquérito civil, um procedimento administrativo que possibilita a investigação e o recolhimento de provas e elementos que convençam o promotor da necessidade ou não de propor uma ação civil pública (Mancuso , 1996). O inquérito civil, inspirado no inquérito policial, é um valioso instrumento, pois facilita a investigação e, ao mesmo tempo, pode tornar descenessária qualquer ação judicial nos casos em que os promotores conseguem promover acordos judiciais com aqueles que figurariam como réus nos 
processos. Nos acordos judiciais, denominados compromissos de ajustamen to de conduta, pessoas físicas ou jurídicas e autoridades públicas se comprometem a tomar iniciativas - quando caracterizada a omissão perante direitos - , a reparardanos cometidos ou a deixar de praticar irregularidades. Caso descumpridos, estes acordos podem sercobrados judicialmente sem a necessidade de uma nova medida judicial. Os compromissos de ajustamento de conduta podem ser realizados na fase do inquérito civil ou apósa propositura da ação civil pública.

As novas atribuições instituídas pela Constituição e pelas leis de proteção aos interesses metaindividuais ocasionaram reorganizações dentro dos Ministérios Públicos estaduais e levaram à criação de novas áreas de especialização, fazendo com que os promotores assumissem gradualmente suas novas funções. Hoje, todos os promotores de justiça que atuam na área de interesses metain dividuais têm à disposição, portanto, uma série de instrumentos que marcam um novo modo de intervenção do Ministério Público em conflitos sociais, imprimindo um grande alcance aos seus atos. Nas promotorias ligadas aos interesses metaindividuais observa-se, porém, uma grande diferença na maneira de empregar procedimentos extrajudiciais e de propor medidas judiciais e no tipo de questões e conflitos considerados importantes. Conforme revelou a pesquisa, uma parte dos promotores de justiça desta área está utilizando instrumentos extrajudiciais e judiciais de modo a inaugurar uma forma de atuação que os transforma em articuladores políticos e acentua o papel do Ministério Público como atorpolítico. Desta forma, a legislação recente traz um tipo novo de intervenção por parte do Ministério Público nos conflitos sociais, mas é possível perceber, além disso, que uma parte dos promotores ligados à área de interesses difusos inaugura um tipo de atuação que transcende o sistema de justiça.

Foi possível distinguir no grupo estudado duas maneiras distintas de agir. Para que a distinção entre estas duas formas de atuação ficasse suficientemente clara, utilizei as características mais marcantes de ambas na definição de dois tipos ideais: promotor de gabinete e promotor de fatos. Eles são propostos aqui como tipos ideais, pois que constru- ídos por meio da ênfase em certas características e elementos encontrados na atuação concreta dos promotores selecionados. Acentuando e realçando algumas características observadas, os tipos promotor de fatos e promotor de gabinete pretendem demarcar diferenças significativas em relação a duas formas distintas de atuação. Assim, considerando cada um dos promotores do grupo estudado, eu poderia classificá-los, talvez, numa escala onde os extremos fossem os tipos definidos acima. Certamente, a maioria ocuparia pontos intermediários nessa escala, nenhum deles encamando exatamente os tipos ideais, uma vez que procedimentos e atitudes que definem ambos os tipos encontram-se entrelaçados na realidade. O tipo ideal é usado como recurso analítico e, como tal, constitui uma "racionalização utópica, que não se encontrajamais ou raramente, na sua pureza, na realidade empírica ou concreta". O tipo ideal é "obtido por racionalização utópica e acentuação unilateral de traços caractenísticos e originais, em vista de dar um significado coerente e rigoroso ao que aparece como confuso e caótico na nossa experiência puramente existencial." (Freund, 1966, pp. 54-55).

Lembro, mais uma vez, que estes tipos estão baseados em formas de atuação desenvolvidas em áreas ligadas à questão dosinteresses metaindividuais- outras áreas de atuação, como a área criminal, embora tenham sofrido mudanças, reservam atribuições e são marcadas por formas de intervenção completamente distintas por parte dos membros do Ministério Público, suscitando questões diversas. Portanto, os tipos promotor de fatos e promotor de gabin ete sugerem ten dências de atuação existentes no Ministério Público dentro do campo dosinteresses metaindividuais, a partir do novo modelo institucional desenhado nos anos 80 e $90 .{ }^{18}$

Definirei o promotor de gabinetecomo aquele que, embora utilize procedimentos extrajudiciais no exercício de suas funções, dá tanta ou mais relevância à proposição de medidas judiciais e ao exame e parecer dos processos judiciais dos quais está encarregado. Mais importante, o promotor de gabinete não usa os procedimentos extrajudiciais como meios de negociação, articulação e mobilização de organismos governamentais e não-governamentais. Já o promotor de fatos, conquanto propo- 
nha medidas judiciais e realize atividades burocráticas ligadas às suas áreas, dá tanta ou mais importância ao uso de procedimentos extrajudiciais, mobilizando recursos da comunidade, acionando organismos governamentais e não-governamentais e agindo como articulador político.

O promotor de gabinete considera que sua principal responsabilidade é dar conta dos processos legais e pareceres ligados à sua área. Nem por isso ele deixa de realizar trabalho de fiscalização, quando sua área exige, e de tomar iniciativas específicas diante de irregularidades e denúncias. Assim, o promotor de gabinete faz "visitas" periódicas a organismos não-governamentais e órgãos governamentais quando necessita averiguar, orientar, informar e ajudar a resolver problemas relacionados, em sua maioria, a irregularidades que chegam ao seu conhecimento. Nas palavras de um dos entrevistados:

O ideal é sempre a gente estar fazendo visitas a entidades e, mesmo na área administrativa (pública), você orientar [...] Mas, o velho chavão: 0 acúmulo de serviço é grande. Então, você vai ficar saindo aí em diligência em detrimento dos processos? Porque processo você tem prazo para ler, você não pode perder um prazo.

O promotor de gabinete acompanha casos particulares, atende ao público, orienta pessoas e organizações, investiga denúncias e defende interesses metaindividuais por meio de inquéritos civis e proposição de ações civis públicas. O envolvimento em iniciativas da comunidade é considerado importante:

Para ser promotor aqui você tem que fazer parte da sociedade. Eu sou rotaryano, por exemplo. $\mathrm{O}$ menor vem aqui, não tem o que comer, eu dou uma cesta básica para ele. Eu já tenho o canal com o clube, eu passo a cesta básica, receitas de remédio, é comum fazer isto. Então, a gente participa.

A participação em ações da comunidade é elogiada, mas o promotor se vê, aqui, como autoridade que deve prioritariamente zelar pelo cum- primento da lei. As atuações conjuntas com órgãos e conselhos governamentais e o trabalho de orientação às pessoas que procuram as promotorias estão ligados a casos individuais e situações específicas. Na área dos direitos da criança, por exemplo, o promotor de gabinete pode notificar pais alcóolatras e convencê-los a entrar em programas especiais, acompanhando o caso por meio de procedimentos extrajudiciais. Na área acima, aparecem como exemplos processos e casos individuais de adoção, abandono, negligência e violência. O envolvimento com organismos governamentais e não-governamentais é visto com cautela:

Procuro não me envolver tanto porque eu tenho que fiscalizar. Então, se eu começar a determinar regras, a participar de uma forma mais ativa, eu vou ter problemas se um dia eu precisar chegare dizer: "olha, não é assim, a lei funciona de outra forma". Como no caso desta entidade, quando eu tive de tomar uma medida contra o dirigente. Quando eu vejo alguma coisa errada, eu oficio o dirigente, mas eu fico mais distante destas questões de participar, de criação, de fazer parte.

Não se pode "cruzar os braços", é preciso "encaminhar para a solução mais adequada possível". Assim, mesmo que a correção de irregularidades por organismos privados e a oferta de programas e políticas pelos poderes públicos estejam longe do "ideal", o promotor de gabin ete trabalha "com o que tem na mão". É preciso fazer o poder público cumprir a lei em questões pontuais e dentro do "possível", mas não se pode acioná-lo para a implantação de todas as políticas públicas inexistentes ou correção de todos os programas em descompasso com a legislação. Esta percepção está vinculada à insatisfação com as respostas do Poder Judiciário a certas medidas judiciais de autoria do MP. A proposição de determinadas ações civis públicas que foram julgadas de forma totalmente contrária às interpretações e expectativas do promotor e de seus pares no Ministério Público alimenta a descrença na possibilidade de se obter a implementação de programas e políticas públicas pela via judicial. Há ceticismo, por exemplo, em relação à proposição de ações civis públi- 
cas contra prefeitos que não instalam os conselhos municipais da criança. Recorre-se ao exemplo de certas ações julgadas improcedentes porque "o Tribunal entendeu que isto faz parte da administração política do prefeito". Ou de ações que, pedindo a inclusão de famílias em programas de auxílio, levam ao mesmo resultado, com juízes e desembargadores argumentando que "a estas ações se sucederiam milhares de outras" e que "o município não teria condições de suportar todas elas". Mesmo quando as ações são julgadas procedentes, resta 0 descontentamento:

Veja bem, a ação civil pública é um instrumento necessário, útil, mas que tem que ser usada racionalmente, em último caso, de modo consciente. Porque não adianta você promover uma ação, ganhar e não levar. Você ganha a ação, muito bonitinho e tal, mas e daí? Então, às vezes, é preferível você ir resolvendo ao jeito brasileiro do que entrar com uma ação. O prefeito, por capricho, diz: “Bom, já que está na justiça, vamos deixar". Então, vão entrando com recurso e vão ganhando tempo. Depois, o tempo passa, passa o problema para outra administração. Estou lembrando de uma ação contra a Prefeitura em que foi combinada uma multa diária. Bom, quem é que vai pagar esta multa? O cidadão! Então, a ação tinha que ser pessoal, tinha que ser contra 0 prefeito mesmo.

Geralmente, o promotor de gabinete instaura o inquérito civil quando percebe que haverá dificuldades na coleta de documentos e provas necessárias à proposição de ações civis públicas. Convencido da necessidade de proporações, o promotor de gabinete prefere não instaurar inquéritos civis, coletando documentos por outros meios. Assim, vê maior probabilidade de acordos judiciais no âmbito das ações civis públicas, embora tente chegar a entendimentos antes da proposição de qualquer medida judicial.

A quantidade de processos e de trabalho burocrático no gabinete, a falta de recursos da administração pública e os limites impostos pela via judicial acabam levando o promotor de gabinete, portanto, a centrar sua atuação na resolução de problemas específicos que são objeto de clara determinação da lei, ou daqueles trazidos por denúncias, como problemas em programas públicos - combate a irregularidades em organizações governamentais e não-govemamentais, assentamentos ilegais na periferia dos municípios, problemas na aceitação de matrícula pelas escolas estaduais etc. $\mathrm{O}$ promotor de gabinete chega até mesmo a questionara abrangência das suas atribuições na defesa de interesses metaindividuais:

O Ministério Público pode proporação civil pública para ver o problema de vagas [nas escolas estaduais]. Só que, na verdade, como aconteceu este ano, efetivamente fica difícil. Entramos com mandado de segurança, não foi dada liminar, aí recorreu para o Tribunal. 0 Tribunal não julgou ainda e nós estamos em agosto! Então, o que adianta?A gente tem que movimentar, a gente tem que cutucar. A gente cutuca, só que fica difícil. Então, acho que você também pode cairno descrédito.[... ]a gente não pode ficarde braços cruzados, a gente tem que fazer alguma coisa. Mas eu também acho o seguinte: ficou tudo para o Ministério Público, de repente. Você tem um problema? Disque Ministério Público! E não é bem isso.

Para o promotor de gabinete, a abrangência de funções e a indefinição decorrente da possibilidade de atuação "fora do processo" na área de interesses metaindividuais - via procedimentos extrajudiciais - perturbam a noção do promotor como autoridade judiciária encarregada prioritariamente de instaurarinquéritos, proporações, cuidar dos processos de sua área e fiscalizar o cumprimento da lei.

A questão aparece de modo invertido se consideramos o promotor de fatos, que lança mão sistematicamente dos procedimentos administrativos ou extrajudiciais. Uma maneira de agir extrajudicialmente é organizar "blitz" ou diligências, requisitando a presença de autoridades locais, órgãos governamentais e organizações não-govemamentais na apuração de irregularidades. As diligências acabam servindo como meio de cobrar ações de autoridades locais e estaduais contra irregularidades e ilegalidades porvezes conhecidas e toleradas: 
Aí eu fui ver a quantas andava o transporte dos trabalhadores rurais, os bóias-frias. Fiz uma blitz: reuní a polícia militar, a polícia rodoviária, 0 Ministério do Trabalho, todos os órgãos ligados. Levei médico, engenheiro para saber as condições, os detalhes. E fiz quatro blitz, vistoriamos quase 300 ônibus: folga na direção, não havia saída de emergência, a porta de trás eles travaram para caber mais pessoas, as enxadas e foices eram transportadas dentro do ônibus, assentos quebrados, enfim, tudo irregular. Mais da metade dos ônibus foram retirados de circulação, os donos foram multados. Eu processei todos os usineiros criminalmente, donos de fazenda e usina. Foram presos em flagrante os motoristas e seguranças.

As diligências aparecem como atos corriqueiros no dia-a-dia do promotor de fatos, ao lado da divulgação da legislação, atendimento ao público, orientação, reuniões, campanhas e até mesmo iniciativas conjuntas com outros órgãos locais. $\mathrm{O}$ uso contínuo destes procedimentos extrajudiciais leva o promotor de fatos a estabelecer um vínculo estreito com determinados órgãos govemamentais no combate a irregularidades - na área do meio ambiente, com a polícia florestal, por exemplo.

O promotor de fatos costuma definir prioridades e estabelecer estratégias, dedicando-se à execução de "projetos". O combate ao trabalho infantil e a irregularidades no transporte escolar, a implantação de conselhos municipais da criança, a instalação de creches e iniciativas visando a programas de reforço escolar nas escolas locais são alguns dos "projetos" existentes na área dos direitos da criança. O combate à evasão escolar é um dos "projetos" adotados. O poder de requisitar documentos e informações das escolas, delegacias de ensino e secretarias permite que o promotor reúna dados sobre os índices de evasão em determinada região ou cidade. A partir daí, ele pode iniciar um trabalho com escolas e pais de alunos, requerendo a presença dos últimos em reuniões ou audiências.

Em outras áreas, o combate à corrupção superfaturamentos, licitações fraudulentas, irregularidades em campanhas eleitorais de prefeitos e vereadores - , a proteção de aldeias indígenas, a proteção do patrimônio histórico, a preservação de trechos da Mata Atlântica, o combate às queimadas, o combate à ocupação e uso irregular do solo, a fiscalização das condições e tarifas dos transportes públicos e a fiscalização de tabelas de planos de saúde são citados como prioridades. Definidas as prioridades e detectadas irregularidades, o promotor pode estabelecer negociações ou participar da elaboração de propostas.

A gente elege alguns temas ambientais de importância vital, como por exemplo resíduos, deposição de resíduos, tratamento de resíduos, poluição das nossaságuas, poluição atmosférica. Então, nós pegamos estes temas que são os mais perturbadores na questão ambiental e, independentemente até de denúncia, nós instauramos protocolados, inquéritos civis de investigação genérica para descobrironde estão os maiores problemas. Daqueles protocolados gerais, podem surgir ações civis públicas para casos específicos, podem surgir acordos se a gente chamar o degradador aqui ou até o poder público, se ele for o problema. Ou até podem surgir propostas de alterações legislativas. Vamos supor que a gente venha a detectar que o problema existe porque a lei está mal feita, mal redigida, ou [... ] não prevê a hipótese, é lacunosa e precisa ser aperfeiçoada.

O promotor de fatos chega a participar da execução de campanhas e da fundação de organizações não-govemamentais voltadas à solução de problemas nas áreas em que atua. Nestas situações, ele articula forças locais e mobiliza recursos da comunidade:

Tudo isso me levou a criar a Casa " $\mathrm{x}$ ", em parceria com a Associação do Comércio e da Indústria de "y", que me deu o material. A Prefeitura deu a mão-de-obra e eu intermediei isto. [O local] Era um albergue que nunca funcionou, que a gente transformou numa casa e os meninos ficavam lá aguardando este período para saber se eles vinham para a Febem ou se não vinham. [... ]Aí isso me levou a criaruma [outra] entidade chamada " $\mathrm{z}$ ". Era uma entidade que se dedicava à execução da medida socioeducativa de prestação de serviços. 
Nas promotorias ligadas à defesa dos interesses metaindividuais, o promotor de fatos prioriza as questões que abrangem um grande número de pessoas ou que estejam ligadas a políticas e programas públicos. Muitas vezes, a partir dos casos individuaisatendidosno gabinete, identifica problemas coletivos e a inexistência de programas governamentais, temas aos quais passa a dar prioridade. Ele define seu papel na defesa de interesses metaindividuais como a nova "vocação" do Ministério Público.

Na defesa de interesses metaindividuais, dependendo do problema ou irregularidade, o promotor de fatos estabelece verdadeiros processos de negociação com prefeitos, secretários municipais e dirigentes de organizações não-governamentais, utilizando os procedimentos extrajudiciais de que dispõe. Quando não tem sucesso, acaba recorrendo a medidas judiciais e propondo ações civis públicas, que podem resultar em acordos judiciais:

Aí, nós estudamos e entramos com uma ação que acabou resultando num programa que deu atendimento aos meninos de rua, várias casas de atendimento, iniciou-se alguma coisa [...] Houve uma colaboração, depois da propositura [da ação civil]. Eles [Secretaria de Assistência Social] chegaram a nos procurar, perguntaram o que nós queríamos [... ] Depois de uma conversa, várias reuniões, tal, eles concordaram com o que nós estávamos pedindo, colocaram uma fórmula para fazer isto e nós fizemos um acordo que foi homologado judicialmente.

Por meio da negociação e dos acordos, 0 promotor defatosinfluencia até mesmo o conteúdo de legislações, políticas e programas municipais de atendimento. Elegendo o contato e o diálogo com os responsáveis por políticas e programas, ele acaba exercendo uma espécie de "pressão formalizada" sobre os administradores públicos. ${ }^{19}$ Neste processo de negociação, as medidas judiciais são utilizadas como último recurso para que as autoridades municipais cumpram a legislação:

A gente senta, mostra, conversa, manda ofício pra cá, negocia, senta, conversa, reunião, reunião, mobiliza opinião, vai fazendo, vai fazendo até que nasce das pessoas, nasce do administrador público, espontaneamente. Quer dizer, espontaneamente não! Eles são provocados, mas por via administrativa: "Olha, se você não fizer no prazo de tanto tempo, vou entrar com ação civil pública”. E não há necessidade de entrar porque eles fazem.

Em determinados momentos, o promotor de fatos instaura inquéritos civis para convencer os prefeitos de que está mesmo disposto a entrar com medidas judiciais. Neste sentido, ele considera que o inquérito civil é o "grande instrumento" do Ministério Público. Ao instaurar um inquérito civil, o promotor de fatos coleta provas e reúne dados que, ao invés de resultarem numa ação civil pública, são utilizados para pressionar e convencer uma determinada autoridade, pessoa física ou juńdica, a estabelecer um acordo judicial. A sua especialização como promotor de justiça e o conhecimento que possui acenca da legislação que protege os interesses metaindividuais parecem assegurar ao promotor de fatos, ademais, uma posição vantajosa nas conversas e na redação dos acordos, que são formalizados judicialmente e passam pelo crivo do Conselho Superior do Ministério Público. O promotor de fatos afirma que os réus privados, ou seja, organizações não-governamentais, empresas e pessoas físicas, são menos resistentes ao fechamento de acordos do que o poderpúblico. As autoridades, órgãos e poderes públicos estaduais e federais são considerados os mais resistentes à negociação ou simplesmente inacessíveis, em função da distância que os separa da maior parte das comarcas, localizadas fora da capital.

O promotor de fatosvê-se não somente como defensor dos interesses e direitos metaindividuais, mas também como agente que deve buscar soluções para "resolver o problema social" relacionado a tais direitos. ${ }^{20}$ A viajudicial é evitada, não só pela lentidão e incerteza das repostas do Poder Judiciário, mas porque o promotor de fatos interpreta 0 seu papel como atividade que transcende o sistema de justiça e requer legitimação na comunidade. Assim, ele atribui grande importância ao trabalho conjunto com organizações não-governamentais, 
órgãos govemamentais e sindicatos. Muitas vezes, coloca-se no papel de articulador de lideranças e organizações locais:

Quando cheguei à cidade "x", verifiquei que não existiam os conselhos e então comecei um trabalho de orientação com relação aos prefeitos no sentido de formar a vontade política para sua instalação. Tanto uma pressão popular quanto uma pressão política para os prefeitos sentirem a necessidade de instalar os conselhos. Foram feitas reuniões com entidades, chamei as entidades, sindicatos, representantes de conselhos de escolas, professores, marquei uma reunião, inclusive chamei os prefeitos, alguns compareceram [...] Tinha um anteprojeto que eu tinha recebido do Centro de Apoio [da Infância], a título de sugestão, de subsídio, e coloquei na mão deles. Este projeto correu o Estado de São Paulo inteiro, cada um colocava ali o que era mais adequado. Não era uma intervenção do Ministério Público, mas uma tentativa de subsidiar quem não tinha condições.

Neste ponto é necessário dizer que tanto 0 promotor de fatos como o promotor de gabinete consideram que as medidas judiciais são o último caminho a ser tomado, uma vez que a via judicial, conhecidamente, é demorada, lenta e nem sempre leva aos resultados pretendidos. Mas a insatisfação com a agilidade e com as respostas do Poder Judiciário leva a posições distintas . $O$ promotor de gabinete tende a evitar medidas judiciais relacionadas aos poderespúblicos, ou seja, demandas que envolvam implementação de programas e serviços públicos. O promotor defatos também evita a viajudicial, mas explora os procedimentos extrajudiciais para mobilizar, articular, pressionar e negociar junto a organismos govemamentais e não-govemamentais, priorizando demandas de impacto coletivo e alargando o seu papel como agente que atua conjuntamente com organizações sociais e grupos locais.

O papel do promotor de justiça ganha então uma nova dimensão: se a via judicial é incapaz de levar a soluções rápidas e satisfatórias, o promotor defatosvolta-se para a via extrajudicial, mostrando uma nova faceta do promotor de justiça, a de articulador político que defende causas coletivas.
Para o promotor de gabinete, a abrangência do papel do Ministério Público na defesa de interesses metaindividuais torna nebulosas as fronteiras entre o universo jurídico - definido, claro e preciso - e o universo extrajurídico de iniciativas diversas permitidas pelos novos procedimentos administrativos e atribuições constitucionais. Uma vez que ele não age e não se vê como articuladorpolítico, sente dificuldades de conciliar o trabalho do dia-a-dia com o campo abrangente de atuação desenhado pelo novo quadro legislativo e institucional. Assim, o promotor de gabinete está consciente da dimensão política do papel do Ministério Público, mas vê limites muito claros à sua atuação. Em primeiro lugar, limites como autoridade judiciária que não acha correto ou não se sente à vontade em atuar como agente político. Em segundo lugar, limites concretos impostos pela ausência de recursos da administração pública e pelas respostas do Poder Judiciánio.

Resumindo, o trabalho burocrático e processual ligado à área de atuação específica do promotor de gabin eteabsorve grande parte do seu tempo e, assim, ele visita e mantém contatos com organizações quando surgem irregularidades ou problemas específicos. Como autoridade encarregada de fiscalizar o cumprimento das leis, o promotor de gabin ete coloca limites claros na atuação conjunta com órgãos governamentais e organizações nãogovernamentais. A participação em iniciativas da comunidade tem a dimensão de um envolvimento pessoal. O promotor de gabinete atende ao público, inicia investigações, apura denúncias, "oficia" autoridades, pessoas jurídicas e físicas, instaura inquéritos civis e propõe ações civis públicas na defesa de interesses metaindividuais. A defesa destes interesses ocorre mais em função das demandas postas ao promotor do que em função dos problemas que o mesmo elegeu como prioritários na sua área de atuação. $\mathrm{O}$ promotor de gabinete não se vê, pois, como autoridade que deve cobrar continuamente do poder público a implementação de políticas e programas sociais.

O promotor de fatos, por sua vez, estabelece contatos, define prioridades, toma iniciativas, articula forças locais e participa de campanhas, mobilizações e eventos. Divulgação de informações, 
atendimento ao público, palestras, orientações e reuniões são procedimentos utilizados freqüentemente. Muitas vezes, as prioridades levam o promotor de fatosa acionar órgãos governamentais e a estabelecer processos de negociação com autoridades públicas, pessoas jurídicas e físicas. Também levam à participação em campanhas, elaboração de projetos e, até mesmo, fundação de organizações não-governamentais. Os inquéritos civis são usados, muitas vezes, para aumentar as chances de fechamento de acordos judiciais. As ações civis públicas são propostas quando os procedimentos extrajudiciais não surtiram efeito ou quando não há possibilidade de contato ou negociação, como nos casos de violação de direitos por órgãos estaduais e federais.

As novas atribuições constitucionais do Ministério Público na defesa de interesses metaindividuais resultam, conforme o grupo estudado, em distintas formas de atuação, devido à abrangência da legislação recente e à independência funcional - que garante, como vimos no cotidiano dos promotores, uma considerável autonomia aos membros do Ministério Público. O tipo promotor de fatos indica a tendência de alargamento das funções dos promotores para muito além da esfera jurídica, tornando-os verdadeiros articuladores políticos nas comunidades em que trabalham. O tipo promotor de gabinete indica a leitura das novas atribuições do promotor dentro das fronteiras da esfera jurídica, definindo-o como agente judiciário cuja prioridade é o trabalho "processual" - propor e acompanhar medidas judiciais - e cuja ação na defesa dos interesses metaindividuais se dá, sobretudo, pela via judicial. De um lado, as novas atribuições constitucionais do Ministério Público são percebidas como fonte de podera serusado na "transformação da sociedade". De outro, causam desconforto devido aos limites impostos pela realidade percebida e às fronteiras imprecisas entre a esfera jurídica e o universo de iniciativas de caráter social e político, exigindo mais do que um agente judiciário supostamente deveria e poderia fazer.

A título de conclusão, pode-se dizer que as modificações recentes no direito brasileiro, com a regulamentação dos interesses metaindividuais, introdução da ação civil pública e procedimentos extrajudiciais, tiveram um impacto significativo nas instituições que administram a justiça, como aponta 0 debate nos últimos anos. Contudo, há muito 0 que ser revelado e discutido sobre as práticas dos operadores do direito em futuras pesquisas so bre 0 Ministério Público e o Poder Judiciário, sobretudo se pensarmos na relação entre a defesa de interesses e direitos afetados pelo funcionamento de políticas públicas e o contexto de redefinição do papel das várias esferas de governo na prestação de serviços e programas sociais.

\section{NOTAS}

1 As epígrafes presentes neste artigo correspondem a trechos de entrevistas realizadas com promotores de justiça do Ministério Público de São Paulo.

2 A Lei da Ação Civil Pública (Lei n ${ }^{\circ} 7.347 / 1985$ ) é considerada o texto "básico" para a tutela judicial dos interesses metaindividuais. Posteriormente, a Constituição de 1988 abriu caminho para a edição de leis que regulamentaram outros interesses e direitos metaindividuais. O Código de Defesa do Consumidor (Lei $\mathrm{n}{ }^{\circ}$ 8.078/1990) foi de fundamental importância, acrescentando dispositivos à Lei da Ação Civil Pública e trazendo outras inovações jurídicas. Depois da Constituição, foram promulgadas ainda a Lei de Proteção aos Deficientes Físicos (Lei $n^{\circ}$ 7.853/1989), a Lei de Proteção aos Investidores do Mercado Imobiliário (Lei $\mathrm{n}^{\circ}$ 7.913/ 1989), o Estatuto da Criança e do Adolescente (Lei n ${ }^{\circ}$ 8.069/1990), a Lei dos Atos de Improbidade Administrativa ou Lei Anticorrupção (Lei n ${ }^{\circ}$ 8.429/1992), a Lei de Defesa do Patrimônio Público (Lei $n{ }^{\circ}$ 8.625/1993) e, finalmente, a Lei de Defesa da Ordem Econômica ou da Concorrência (Lei $\mathrm{n}^{\circ}$ 8.884/1994). No texto, utilizo 0 termo leis de proteção aos interesses metaindividuais para referir-me ao conjunto das leis acima .

3 O Ministério Público de São Paulo é o maior do país. Segundo dados fornecidos pela Procuradoria-Geral de Justiça do MP-SP, 1.337 promotores de justiça e 202 procuradores de justiça faziam parte da instituição em 1998. Do total de promotores, 812 atuavam no interiore 525, na capital - os procuradores de justiça atuam somente na capital do estado. Em 1997, 73,7\% dos membros do Ministério Público de São Paulo pertenciam ao sexo masculino e $26,3 \%$, ao sexo feminino, mas 0 ingresso de mulheres aumentaria substancialmente nos anos 90 (Morais, 1996). A composição etária mostra que mais da metade possuía até 40 anos de idade (NEV, 1998). Estes dados apontam um importante fenômeno que vem ocorrendo no MP paulista: a renovação na carreira depois da promulgação da Constituição, hoje formada predominantemente por jovens. $\mathrm{O}$ fenômeno se repete em outros estados (Sadek, 1997). 
4 Interesses e direitos individuais homogêneos podem ser definidos como direitos individuais que, em função da inserção do indivíduo em determinado contexto social, criam um núcleo comum de questões de direito ou de fato entre os sujeitos, como, por exemplo, o direito de cada criança à matrícula em escolas públicas. Interesses e direitos coletivos são interesses comuns a uma coletividade de pessoas, tais como os interesses que reúnem os moradores de um conjunto residencial. Interesses e direitos difusos, porsua vez, referem-se a grupos menos determinados de pessoas, não ligadas, necessariamente, por um vínculo de direito ou de fato preciso, como no caso dos consumidores de determinado bem lesados pela empresa que o produziu. Cf. Mancuso (1997), Mazzilli (1992) e Grinover (1984).

5 De acordo com Bobbio (1978, p. 63), a "especificação ocorreu em relação seja ao gênero, seja às várias fases da vida, seja à diferença entre estado normal e estados excepcionais na existência humana. Com relação ao gênero, foram cada vez mais reconhecidas as diferenças específicas entre a mulher e o homem. Com relação às várias fases da vida, foram-se progressivamente diferenciando os direitos da infância e da velhice, porum lado, e os do homem adulto, por outro. Com relação aos estados normais e excepcionais, fez-se valer a exigência de reconhecer direitos especiais aos doentes, aos deficientes, aos doentes mentais etc."

6 Com base nas funções já exercidas pelos promotores na área cível - atendimento ao público, funções conciliativas, assistência judiciária e fiscal da lei - , membros do MP defenderam que a instituição assumisse a tutela dos interesses coletivos e difusos. Mas as atribuições do MP na defesa dos interesses metaindividuais não foram conquistadas sem reação da categoria a outros anteprojetos de lei, que previam a criação de órgãos nãojudiciários para exercer a defesa do cidadão e controlar os abusos da administração pública. Este aspecto é discutido no primeiro capítulo da minha tese (Silva, 1999). Registre-se que as associações legalmente constituídas também estão legitimadas a promover ações civis públicas para defender os interesses metaindividuais. Entretanto, devido ao custo financeiro e à especialização técnica exigida por causas desta natureza, o Ministério Público aparece como o autor da maior parte das medidas judiciais em defesa dos interesses metaindividuais no Estado de São Paulo. Provavelmente, esta tendência também ocorre nos demais estados brasileiros.

7 Interessada na atuação do MP na defesa de direitos da coletividade, sobretudo direitos afetados pelo funcionamento de serviços e políticas públicas, selecionei promotores de justiça que haviam proposto medidasjudiciais contra o poder público em defesa dos direitos da criança e do adolescente no período 1990-1997. Foram selecionados e entrevistados 21 promotores -4 mulheres e 17 homens - no interior e na capital do Estado de São Paulo. À época das entrevistas, 11 atuavam na área da infância e juventude, dois na área de meio ambiente, um na área de habitação e urbanismo, um na área de cidadania e o último acumulava funções nas áreas de cidadania e consumidor - todas elas envolvendo questões relativas a interesses metaindividuais. Entre os cinco restantes, dois ocupavam cargos de confiança na Procuradoria-Geral e na Corregedoria-Geral do MP, dois atuavam na área criminal e um, finalmente, havia se aposentado. Foram realizadas entrevistas abertas e gravadas nos meses de agosto e setembro de 1997 nas localidades onde os promotores trabalhavam, ocasião em que pude interagir com os mesmos, acompanhar o seu trabalho, fazer observações e recolher dados. Em 1998, visando à obtenção de informações complementares, foram feitas outras entrevistas no MP paulista. Além de projetos de lei em tramitação, documentos e jornais do período 1982-1998, analisei cópias de 43 ações civis públicas de autoria dos promotores entrevistados e cópias de acórdãos do Tribunal de Justiça do Estado de São Paulo referentes a medidas judiciais visando garantir a matrícula de crianças em escolas estaduais.

8 Não se pretende dar a este discurso o peso de uma ideologia organizacional, esta sim "um conjunto sistemático de idéias, com ações conseqüentes, que servem aos propósitos de criação e uso de uma organização" (Schurmann, 1968, p. 18). Em São Paulo, a imagem do Ministério Público paulista como instituição "que se fez" quase "sem interferências externas" é amplamente divulgada pelos promotores e procuradores de justiça. Nas representações dos promotores - impossíveis de serem discutidas neste artigo - o MP aparece como a vanguarda do sistema de justiça, devido à participação ativa nas propostas legislativas que ampliaram as suas atribuições, distinguindo-se, assim, do Poder Judiciário, visto pela maior parte dos promotores entrevistados como instituição refratária a mudanças e alheia às transformações sociais.

9 Promotor de justiça é o membro do Ministério Público que atua junto à primeira instância, promovendo a ação penal pública, requisitando da polícia o inquérito policial e diligências investigatórias, zelando para que os serviços e poderes públicos respeitem os direitos assegurados aos cidadãos pela Constituição, abrindo inquéritos civis e propondo ações civis públicas em defesa de interesses da coletividade, entre outras atribuições. Procurador de justiça é o membro do Ministério Público que atua em segunda instância, oficiando junto aos tribunais.

10 Em relação à independência funcional, por exemplo, promotores de justiça devem observar instruções e regulamentos fixados pelos órgãos superiores da instituição nas atividades-meio (elaboração e remessa de relatórios, comunicados etc.). O procurador-geral de justiça, ademais, tem funções importantíssimas e de enorme alcance para os membros do Ministério Público, como a elaboração do orçamento anual do MP, a indicação de promotores e procuradores para cargos de confiança, a criação e a extinção de cargos etc. Cf. Mazzilli (1997).

11 Os concursos públicos para recrutamento de membros do Ministério Público constam de teste de conhecimentos gerais e noções de direito, prova escrita sobre 
matérias específicas, exame psicotécnico, prova oral, entrevista e avaliação de títulos. A banca do concurso, composta pelo procurador-geral de justiça e quatro procuradores eleitos pelo Conselho Superior do MP-SP, conta com um representante da Ordem dos Advogados do Brasil. A conduta e o desempenho dos substitutos, durante o período de dois anos, são avaliados pela Corregedoria-Geral e, em sendo aprovados, estes passam por um processo de vitaliciamento, ou seja, adquirem vitaliciedade no cargo. Cf. Mazzilli (1987) e APMP (1996).

12 O termo comarca indica, segundo a Enciclopédia Saraiva de Direito, "o território, a circunscrição territorial, compreendido pelos limites em que termina a jurisdição de um juiz de direito. Assim, cada um dos distritos ou circunscrições judiciárias em que se divide 0 estado federado, de acordo com a sua Lei de Organização Judiciária, se denomina comarca [... ]" (França, 1977, p. 153). As comarcas de primeira, segunda e terceira entrâncias, localizadas fora da capital, são comumente designadas pelos promotores como comarcas do interior. Os promotores do grupo estudado estavam atuando nas seguintes comarcas: Cubatão, Guarulhos, Marília, Mirassol, Ribeirão Preto, Santos, São José do Rio Preto, São Paulo e Votuporanga. Dos 21 entrevistados, 12 estavam atuando em comarcas do interior (primeira, segunda e terceira entrâncias), 8 na comarca de entrância especial (capital), e 1 havia se aposentado.

13 O Conselho Superiordo Ministério Público de São Paulo é responsável pelas promoções e remoções dos membros da instituição, que podem se candidataraos cargos desde que possuam "dois anos de estágio (exercício) na respectiva entrância, categoria ou cargo" (Mazzilli, 1998). De modo bem simplificado, pode-se dizer que o critério de antiguidade beneficia o candidato mais antigo na entrância anterior. O critério de merecimento envolve a avaliação da conduta, operosidade e dedicação ao cargo, segurança e presteza nas manifestações processuais, participação em listas anteriores de merecimento, freqüência e aproveitamento em cursos oficiais ou em reconhecidos cursos de aperfeiçoamento (Mazzilli, 1996). Os promotores selecionados apresentavam tempo de carreira que variava de 26 a 8 anos. 0 promotor aposentado permaneceu no Ministério Público por 17 anos, carreira considerada curta. Dos 3 promotores que haviam ingressado mais recentemente no MP, com 8 anos de carreira, 1 estava em comarca de segunda entrância - por sinal, o único - e os 2 restantes, na comarca de entrância especial. 0 tempo de carreira dos 11 promotores que trabalhavam em comarcas de terceira entrância variava de 10 a 26 anos. Os 8 promotores que atuavam na comarca de entrância especial (capital) tinham de 8 a 20 anos de carreira. Por fim, dentre os entrevistados havia promotores com 11 anos de carreira que ocupavam cargos bastante especializados na comarca de entrância especial, ao mesmo tempo em que o promotor mais antigo do grupo, com 26 anos de Ministério Público, atuava numa comarca de terceira entrância, tendo decidido encerrar aí sua carreira.
14 Todas as palavras ou expressões entre aspas, bem como os parágrafos destacados no texto correspondem a termos ou trechos de entrevistas realizadas com os promotores selecionados.

15 A referência ao MP como "órgão de proteção aos fracos" é feita por Dinamarco, Grinover e Araújo Cintra, ao comentarem as funções tradicionalmente exercidas pela instituição no sentido de assegurar proteção àqueles considerados incapazes e impossibilitados de agir e compreender (Grinover et al., 1988; Mazzilli, 1987). A respeito da terminologia "promotor público", consultar Mazzilli (1996). A prestação de assistência judiciária pelos membros do Ministério Público era determinada pela Lei Complementar Federal $n{ }^{\circ} 40(14 / 12 / 1981)$ e pela Lei Complementar $n^{\circ} 304(28 / 12 / 1982)$, ambas substituídas pelas novas leis orgânicas nacional e estadual do Ministério Público.

16 Embora os promotores gozem, no plano formal, de autonomia e independência funcional, é preciso chamar a atenção para a existência de órgãos de apoio do MPSP que, em algumas áreas, acabam identificando áreas prioritárias de atuação, monitorando legislações e políticas públicas. Os centros de apoio operacional, por exemplo, foram criados no MP-SP na década de 70 e hoje são definidos como órgãos que devem estimular o intercâmbio entre promotorias de justiça da mesma área, remeter informações técnico-jurídicas a promotores e órgãos do MP e estabelecer contatos com organismos não-governamentais da área correspondente. Conquanto os promotores não tenham obrigação de participar das iniciativas e atividades dos centros de apoio, estes podem funcionar como um centro de articulação interna e externa, como ocorreu nas áreas do consumidor, meio ambiente e criança e adolescente em São Paulo. Os centros de apoio citados cumpriram um papel importante na elaboração de legislações estaduais e nacionais, formando grupos de trabalho e estabelecendo estratégias de atuação junto aos promotores. Ressalte-se que outros centros de apoio podem acabar cumprindo uma função meramente burocrática, o que vai depender das orientações da política do procuradorgeral de justiça e dos profissionais que estão à frente do órgão. Porfim, as promotorias são unidades administrativas ocupadas por um ou mais promotores que atuam numa área determinada. Note-se que é vedado às promotorias de justiça e aos centros de apoio exercerem funções que não sejam administrativas. Assim, estes órgãos não podem realizar funções de execução, ou seja, deliberações funcionais, exercício de competência ou atribuições funcionais, exclusivas dos membros do MP.

17 De acordo com o texto da Lei da Ação Civil Pública (Lei $\mathrm{n}^{\circ}$ 7.347/85), mesmo havendo uma ação civil pública considerada improcedente por falta de provas, é possível que o mesmo argumento seja utilizado em outra ação, o que corresponde a uma ampliação dos "limites subjetivos da coisa julgada". Este aspecto rompe com um dos princípios tradicionais do processo civil, o princípio da autoridade limitada da coisa julgada, se- 
gundo o qual a decisão judicial só atinge as partes processualmente representadas, não afetando a terceiros (Benjamin, 1995). Deste modo, a legislação buscou a adequação dos procedimentos judiciais às especificidades dos interesses difusos, que não estão limitados às partes. A lei acima estabeleceu ainda a inversão do ônus da prova (o réu, e não a parte autora do processo, tem de provar que não cometeu a lesão) e a irrelevância da licitude da atividade (mesmo que a atividade não seja ilícita, o seu autor será responsabilizado se causardanos aos interesses difusos), entre outras inovações importantes. Cf. Mancuso (1997).

18 É preciso lembrar que a área criminal, a área de atuação mais tradicional do promotor de justiça, ocupa aproximadamente metade dos membros do Ministério Público de São Paulo. Existem diferenças significativas no tipo de trabalho desempenhado pelos promotores na área criminal, nas áreas cíveis ligadas à questão dos interesses metaindividuais e na chamada "parte cível tradicional" - que consiste em atividades mais burocráticas relacionadas, por exemplo, a pareceres em habilitações matrimoniais e participação em determinados processos legais envolvendo interesses individuais. Registre-se que 12 dos 21 entrevistados estavam atuando no interior, onde o acesso à área de intereses difusos e coletivos, devido ao número de vagas existentes, é mais fácil do que na capital.

19 Na área dos direitos da criança, a instalação dos conselhos municipais e dos conselhos tutelares, previstos no Estatuto da Criança como parte da política local de atendimento ao segmento infanto-juvenil, ilustra exemplarmente a "pressão" dos promotores sobre os prefeitos. A instalação e funcionamento dos conselhos acima foi, ao lado dos processos relativos à educação e promoção social, um dos três problemas que mais provocaram a propositura de medidas judiciais contra 0 poder público pelo MP paulista na área da infância, entre 1990 e 1997. Consideradas apenas as medidas propostas contra o poder público municipal durante este período, verifica-se que os conselhos constituem a maior fonte de processos judiciais dos promotores contra as prefeituras. Das 135 medidas judiciais propostas na área dos direitos da criança no período 1990-1997, 47 possuem autoridades e órgãos públicos municipais como réus. Destas, 21 têm como objeto o funcionamento e instalação dos conselhos municipais e tutelares e do fundo municipal da criança.

20 Nas imagens construídas pelos promotores estudados, transparece a convicção de que os interesses da sociedade não são devidamente representados e defendidos na arena política. De acordo com esta visão, os políticos primam pela defesa de seus próprios interesses, o poder público não atende as demandas dos cidadãos e a sociedade mostra-se frágil e desorganizada. O Ministério Público viria, pois, "preencherum vácuo", fiscalizando políticos e a administração pública e defendendo os interesses da sociedade. Assim, boa parte dos promotores estudados se vê como "agentes de transformação social", aspecto que não terei condições de desenvolver neste espaço.

\section{BIBLIOGRAFIA}

APMP - ASSOCIAÇÃO PAULISTA DO MINISTÉRIO PÚBLCO. (1996), CD-ROM institucional. São Paulo.

ARANTES, Rogério. (1999), “Direito e política: o Ministério Público e a defesa dos direitos coletivos". Revista Brasileira de Ciências Sociais, 39, 14: 83-102.

BENJAMIN, Antônio H.V. (1995), “A insurreição da aldeia global contra o processo civil clássico: apontamentos sobre a opressão e libertação judiciais por meio do ambiente e do consumidor", in Edis Milaré (org.), A ação civil pública, São Paulo, Ed. Revista dos Tribunais.

BOBBIO, Norberto. (1978), A era dos direitos. São Paulo, Campus.

BOURDIEU, Pierre. (1989), "A força do direito: elementos para uma sociologia do campo jurídico", in P. Bourdieu, O poder simbólico, Lisboa, Difel.

CAPPELLETTI, Mauricio etal. (orgs.). (1981), Access to the justice and the welfare state. Sijthoff, Alphen aan den Rijn.

FRANÇA, R. Limongi. (1977), Enciclopédia Saraiva de Direito. São Paulo, Saraiva, vols. 61 e 62.

FREUND, Julien. (1966), Sociologie de Max Weber. Paris, Presses Universitaires de France.

GEERTZ, Clifford. (1989), A interpretação das culturas. Rio de Janeiro, LTC.

GOMES, M.A. (1989), "Ministério Público na Constituição de 1988: breves anotações". Justitia, 145, 51: 64-78.

GRINOVER, Ada P. (org.). (1984), A tutela dosinteresses difusos. São Paulo, Max Limonad.

GRINOVER, Ada P. et al. (orgs.). (1988), Participação e processo. São Paulo, Ed. Revista dos Tribunais.

KOTZ, H. (1981), "Public interest litigation: a comparative survey", in Mauricio Cappelletti et al. (orgs.), Access to the justice and the welfare state, Sijthoff, Alphen aan den Rijn.

MACEDO JR., Ronaldo P. (1995), "A evolução institucional do Ministério Público brasileiro", in Maria Teresa Sadek (org.), Uma introdução ao estudo da justiça, São Paulo, Idesp/Sumaré.

MANCUSO, Rodolfo de C. (1996), Ação civil pública. São Paulo, Ed. Revista dos Tribunais. 
(1997), Interesses difusos: conceito elegitimação para agir. São Paulo, Ed. Revista dos Tribunais.

MAZZILL, Hugo N. (1987), Manual do promotor de justiça. São Paulo, Ed. Revista dos Tribunais.

. (1992), A defesa dosinteresses difusos em juízo. São Paulo, Ed. Revista dos Tribunais.

(1996), Regime jurídico do Ministério Público. São Paulo, Ed. Revista dos Tribunais.

(1997), "Independência do Ministério Público", in Antônio A.C. Ferraz (org.), Ministério Público: instituição e processo, São Paulo, Atlas.

. (1998), Introdução ao Ministério Público. São Paulo, Saraiva.

MORAIS, T.A. de. (1996), "Histórico dos concursos de ingresso na carreira do Ministério Público de São Paulo", in APMP, CD-ROM institucional, São Paulo.

NEV - Núcleo de Estudos da Violência da USP. (1998), Pesquisa de formação de profissionais do Judiciário, do Ministério Público e das Polícias Civil e Militar no Estado de São Paulo. Relatório preliminar, São Paulo.

PIERUCCI, Antônio F. de O. (1984), Democracia, Igreja e voto: o envolvimento dos padres de paróquia de São Paulo nas eleições de 1982. Tese de doutorado. São Paulo, Universidade de São Paulo, datilo.

SADEK, Maria T. (org.). (1995), Uma introdução ao estudo da justiça. São Paulo, Idesp/Sumaré.

. (1997), O Ministério Público e a justiça no Brasil. São Paulo, Idesp/Sumaré.

SCHURMANN, F. (1968), Ideology and organization in communist China. Berkeley/Los Angeles, University of California Press.

SILVA, Cátia A.P. da. (1999), Novasfacetas da atuação dos promotores de justiça: um estudo sobre o Ministério Público e a defesa dos interesses sociais. Tese de doutorado. São Paulo, Universidade de São Paulo, datilo.

SOUSA SANTOS, Boaventura. (1988), O discurso e o poder: ensaio sobre a sociologia da retórica jurídica. Porto Alegre, Antônio Sérgio Fabris.

(1995), Pela mão de Alice: o social e o político na pós-modernidade. São Paulo, Cortez. 